\title{
Interleukin-10-Producing DC-10 Is a Unique Tool to Promote Tolerance Via Antigen-Specific T Regulatory Type 1 Cells
}

\author{
Michela Comi, Giada Amodio and Silvia Gregori* \\ San Raffaele Telethon Institute for Gene Therapy (SR-Tiget) San Raffaele Scientific Institute IRCCS, Milan, Italy
}

The prominent role of tolerogenic dendritic cells (tolDCs) in promoting immune tolerance and the development of efficient methods to generate clinical grade products allow the application of tolDCs as cell-based approach to dampen antigen (Ag)-specific T cell responses in autoimmunity and transplantation. Interleukin (IL)-10 potently modulates the differentiation and functions of myeloid cells. Our group contributed to the identifica-

OPEN ACCESS

Edited by:

Luis Graça,

Universidade de

Lisboa, Portugal

Reviewed by:

Muriel Moser,

Université libre de Bruxelles,

Belgium

Ana lzcue,

Uniklinik RWTH Aachen,

Germany

*Correspondence:

Silvia Gregori

gregori.silvia@hsr.it

Specialty section:

This article was submitted to Immunological Tolerance and Regulation,

a section of the journal

Frontiers in Immunology

Received: 15 November 2017 Accepted: 20 March 2018

Published: 06 April 2018

Citation:

Comi M, Amodio G and Gregori S (2018) Interleukin-10-Producing

DC-10 Is a Unique Tool to Promote

Tolerance Via Antigen-Specific

T Regulatory Type 1 Cells.

Front. Immunol. 9:682.

doi: 10.3389/fimmu.2018.00682 tion of IL-10 as key factor in inducing a subset of human tolDCs, named dendritic cell (DC)-10, endowed with the ability to spontaneously release IL-10 and induce Ag-specific T regulatory type 1 (Tr1) cells. We will provide an overview on the role of IL-10 in modulating myeloid cells and in promoting DC-10. Moreover, we will discuss the clinical application of DC-10 as inducers of Ag-specific Tr1 cells for tailoring Tr1-based cell therapy, and as cell product for promoting and restoring tolerance in T-cell-mediated diseases.

Keywords: interleukin-10, dendritic cells, tolerance, DC-10, T regulatory type 1 cells

\section{INTRODUCTION}

Interleukin (IL)-10 is a powerful anti-inflammatory cytokine that plays an essential role in dampening immune responses and in preventing chronic inflammatory pathologies (1). Deficiency or aberrant expression of IL-10 or IL-10 receptor (IL-10R) enhance inflammatory responses to microbial challenge and lead to the development of inflammatory bowel disease $(2-4)$ and several autoimmune diseases [as reviewed in Ref. $(5,6)$ ]. Some pathogens can harness the immunosuppressive capacity of IL-10 to limit host immune responses, leading to persistent infection [as reviewed in Ref. (7)].

Human IL-10 was cloned (8) from a tetanus toxin-specific CD4 $4^{+}$human T-cell clone isolated from peripheral blood of a patient with severe combined immunodeficiency successfully transplanted with fetal liver and thymus, who spontaneously developed tolerance (9). From its discovery, IL-10 has been demonstrated to be produced by almost all leukocytes, including all $\mathrm{T}$ cell subsets, monocytes, macrophages, dendritic cells (DCs), B and natural killer (NK) cells, mast cells, neutrophils, and eosinophils [reviewed in Ref. (10)]. In addition, epithelial cells and keratinocytes can also secrete IL-10 in response to infection or tissue damage as well as tumor cells $(11,12)$.

Interleukin-10 upon interaction with IL-10R regulates the expression of several genes resulting in the downregulation of pro-inflammatory mediators, the inhibition of antigen (Ag) presentation, and the upregulation of immune-modulatory molecules. Overall, IL-10 modulates antigenpresenting cells (APCs), inhibits, directly and indirectly, effector T cell proliferation and cytokine production, and promotes regulatory cell differentiation [reviewed in Ref. $(13,14)$ ]. 
Here, we present an overview on the role of IL-10 in promoting the differentiation of myeloid regulatory DCs, focusing on the induction of a subset of human tolerogenic (tol) DCs, termed DC-10. Moreover, we discuss the role of DC-10 in modulating $\mathrm{T}$ cell responses in vitro and in vivo and the current clinical application of DC-10 for cell-based therapeutic approaches.

\section{IL-10 AND MODULATION OF MYELOID CELLS}

Interleukin-10 signaling in monocytes/macrophages and DCs converges, via several mechanisms, to regulate nuclear transcriptional events, inducing the initiation of homeostatic and anti-inflammatory programs. IL-10 interacts with a tetrameric receptor consisting of two IL-10R $\alpha$ and two IL-10R $\beta$ subunits. IL-10R $\alpha$ binds IL-10, while IL-10R $\beta$, interacting with accessory molecules, mediates intracytoplasmic signals (14). IL-10/IL-10R interaction leads to phosphorylation of Janus kinase 1 (JAK1) associated with IL-10R $\alpha$ and of Tyrosine Kinase 2 (TYK2), associated with IL-10R $\beta$. These kinases further phosphorylate two tyrosine residues located on the intracellular domain of IL-10R $\alpha$ that act as temporary docking sites for STAT3 and STAT1 (15). Phosphorylated STATs homo/hetero-dimerize and translocate into the nucleus, where they bind to STAT-responsive genes $(1,16)$. Although the mechanisms underlying the IL-10/ STAT3-mediated responses are still to be fully understood, it has become evident that both IL-10 and STAT3 are required for anti-inflammatory responses. In macrophages, one of the major effects of IL-10/STAT3-mediated signaling is the transcription inhibition of up to $20 \%$ of the LPS-induced genes (17). This antiinflammatory activity is mediated primarily by STAT3 that, upon nuclear translocation, promotes the expression of specific genes, including those encoding for transcription factors, the ultimate effectors of the IL-10-mediated anti-inflammatory responses (18). Among molecules involved in inhibiting activation of myeloid cells, BCL3 has been shown to suppress LPS-induced TNF- $\alpha$ expression by inhibiting NF-kB (19), and NFIL3 has been demonstrated to specifically target a distal enhancer of $I l 12 b$ and repress IL-12p40 expression (20, 21). IL-10/STAT3-mediated signal in macrophages promotes the expression of suppressor of cytokine signaling 3 (SOCS3) (22), a member of the SOCS protein family that plays important roles in the negative regulation of cytokine signaling pathways (23) (Figure 1). Although both IL-10 and IL- 6 promote via STAT3 the expression of SOCS3, its inhibitory effects are restricted to IL-6R-mediated signaling (16). This evidence indicates that SOCS3 plays a role in regulating the pro-inflammatory effects of IL-6 (24).

In macrophages, upon activation with LPS or TNF- $\alpha$, IL-10 prevents the activation and nuclear translocation of the classical NF-kB by inhibiting IkB kinase (IKK) activity (25-27), and hampers NF-kB DNA binding (28). This mechanism has been applied also to in vitro differentiated myeloid DCs, in which pre-treatment with IL-10 results in NF-kB inhibition that correlates with suppression of IKK and Akt activities (29). Similarly, the addition of IL-10 during TLR-mediated activation of monocyte-derived
DCs hinders MyD88 signaling, leading to the downregulation of NF-kB family members c-Rel and p65, and interferon regulatory factor (IRF)-3 and IRF-8, an effect mediated by the inhibitory activity on the PI3K/Akt pathway (30). The IL-10-mediated inhibition of the PI3K/Akt signaling pathway leads also to the activation of the glycogen synthase kinase 3 beta (GSK3beta) and of the downstream microphthalmia-associated transcription factor (MITF) that translocates to the nucleus and drives the expression of the inhibitory molecule glycoprotein (GP) NMB (30) (Figure 1). At steady state and upon activation of myeloid cells, IL-10 signaling induces the selective nuclear translocation of NF-kB p50/p50, overall preventing the expression of several pro-inflammatory mediators, including IL- 6 and MIP-2 $\alpha$ (27). Interestingly, in activated macrophages, BCL3, a member of the $\mathrm{IkB}$ protein family localized in the nucleus and tightly associated with NF-kB p50 (31), acts to repress the transcription of proinflammatory cytokines, and positively regulates the expression of IL-10 (32).

An additional effect of IL-10 in myeloid cells is the downregulation of $\mathrm{MHC}$ class II $(33,34)$ and costimulatory molecules (35) expression (Figure 1). The mechanism of IL-10-mediated deregulation of MHC class II expression involves the transport inhibition of mature and peptide-loaded MHC class II complex to the plasma membrane (36). These IL-10-mediated effects are completely reversed by blocking STAT3 (37), although the role of STAT3 in these mechanisms has not been fully elucidated.

Interleukin-10 regulates at post-transcriptional levels, via micro (mi)RNAs, the expression of pro-inflammatory cytokines (38). IL-10 inhibits the expression of LPS-induced miR155, allowing the expression of $\mathrm{SH}-2$ containing inositol $5^{\prime}$ polyphosphatase 1 (SHIP-1), which in turn negatively regulates PI3K-mediated activation of NF-kB and MAPK, and switches off the pro-inflammatory response (39). On the contrary, upon LPS stimulation, IL-10 rapidly and transiently enhances miR146b and sustains miR187 expression in myeloid cells. miR187 acts as negative modulator of LPS responses by directly limiting TNF- $\alpha$ production at posttranscriptional level and by reducing IL- 6 and IL-12p40 transcription via silencing the transcription factor IkB (40) (Figure 1). miRNAs have been also involved in regulating IL-10 expression upon LPS-mediated activation: upregulation of miR21 indirectly increases IL-10 production via downregulation of programmed cell death 4 (41). Overall, these evidences indicate that, through a complex network of miRNAs, IL-10 drives anti-inflammatory responses by upregulating miR146b and miR187 and by downregulating pro-inflammatory miRNAs, such as miR155.

In summary, IL-10 directly and indirectly, via inducing STAT3 responsive genes and/or modulating NF-kB and MAPK activities, inhibits pro-inflammatory cytokine gene transcription in activated myeloid cells, and the expression of MHC class II and costimulatory molecules, overall preventing the ability of myeloid cells to efficiently present Ags to T cells and to activate effector T cells [reviewed in Ref. (7)].

Besides being an anti-inflammatory mediator, IL-10 promotes the expression of several tolerogenic molecules in human monocytes, macrophages, and DCs, including IL-10 itself (15), heme-oxygenase (HO-1) $(42,43)$, and immunoglobulin-like transcript 3 (ILT3) and ILT4 (44). HO-1 is a protein of heme 


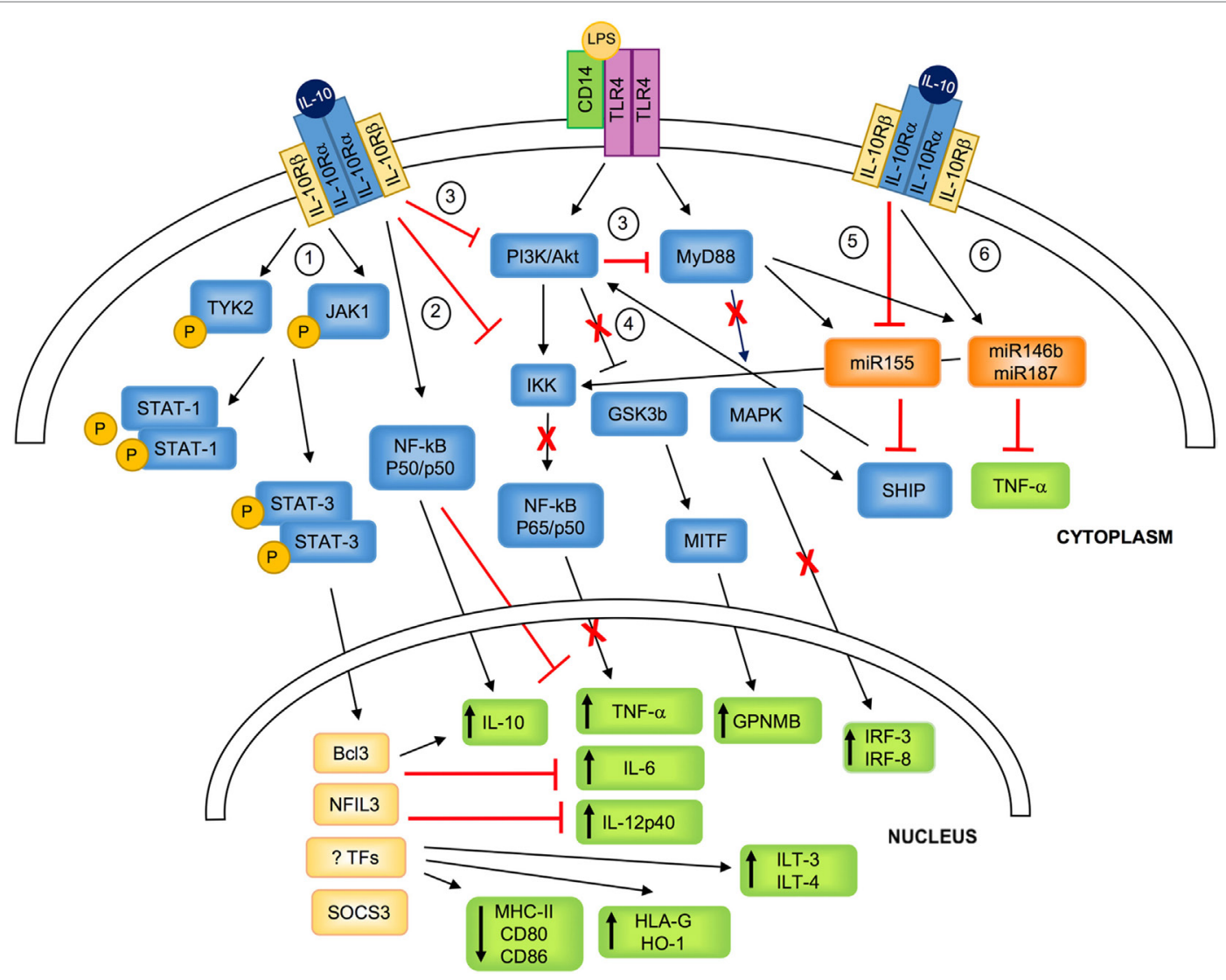

FIGURE 1 | IL-10-mediated modulation of myeloid cells. IL-10 binds to a tetrameric receptor consisting of two IL-10R $\alpha$ and two IL-10R $\beta$ subunits. 1. IL-10/IL-10R interaction leads to JAK1 and TYK2 phosphorylation and the consequent STAT3 and STAT1 phosphorylation. P-STATs, and in particular P-STAT3, dimerizes and translocates to the nucleus, where it promotes the transcription of specific molecules (i.e., SOCS3) or transcription factors (i.e., BCL3 and NFIL3), and inhibits the transport of MHC class II to the plasma membrane. 2. IL-10 signaling inhibits LPS-mediated activation of IKK that in turn prevents NF-kB-p65/p50 nuclear translocation and the expression of pro-inflammatory cytokine. In parallel, IL-10 promotes the selective NF-kB-p50/p50 nuclear translocation, which concurs in downregulating pro-inflammatory cytokine expression, and, in association with BCL3, promotes IL-10 expression. 3. IL-10 inhibits PI3K/Akt pathway that prevents LPS-mediated activation of MyD88, resulting in the inhibition of the expression of IRF-3 and IRF-8. 4. IL-10-mediated inhibition of PI3K/Akt pathway leads to GSK3 $\beta$ and MITF activation, responsible for the upregulation of the transcription of GPNMB. 5. IL-10 downmodulates LPS-induced expression of miR155, which directly inhibits SHIP1 and favors the negative regulation of TLR4 signaling by counteracting PI3K activity. 6. IL-10 enhances LPS-mediated induction of miR146b and miR187, which post-transcriptionally regulate mRNA encoding for TNF- $\alpha$ and reduce IL-6 and IL-12p40 transcription via inhibition of the transcription factor IkB. TYK, tyrosine kinase; JAK, Janus kinase; PI3K, phosphoinositide 3-kinase; Akt, protein kinase B; MyD88, myeloid differentiation primary response 88; STAT, signal transducer and activator of transcription; IKK, IKB kinase; NF-kB, nuclear factor kappa-light-chain-enhancer of activated B cells; GSK3 $\beta$, glycogen synthase kinase 3 beta; MITF, microphthalmia-associated transcription factor; MAPK, mitogen-activated protein kinase; SHIP1, SH-2 containing inositol 5' polyphosphatase 1; Bcl3, B-cell lymphoma 3-encoded protein; NFIL3, nuclear factor interleukin 3; TFs, unknown transcription factors; SOCS, suppressor of cytokine signaling; GPNMB, glycoprotein NMB; HO-1, heme-oxygenase-1; ILT, immunoglobulin-like transcript; IRF, interferon regulatory factor; IL-10R, IL-10 receptor.

degradation pathway playing a central role in tissue homeostasis and protection against oxidative stress (42). HO-1 is involved in the polarization of anti-inflammatory macrophages, which in turn acquire the ability to secrete high levels of HO-1 $(45,46)$. In human DCs, HO-1 inhibits their ability to stimulate allogeneic (allo) T cells and promotes their suppressive effects (43). ILT3 and ILT4 display a long cytoplasmic tail containing immunereceptor tyrosine-based inhibitory motifs that upon binding to HLA class I molecules transduce a negative signal through the recruitment of the tyrosine phosphatase SHP-1. This leads to inhibition of NF-kB activation and, consequently transcription of genes encoding for costimulatory molecules $(47,48)$. Finally, IL-10 upregulates the transcription of the non-classical HLA class
I molecule HLA-G $(49,50)$, one of the ILT4 ligands (47) with known immune-modulatory functions.

Overall, IL-10 via several mechanisms regulates activation and function of myeloid cells, thereby playing an important role in modulating immune responses in healthy and pathological conditions.

\section{IL-10-MEDIATED MODULATION OF MONOCYTE-DERIVED DCs}

Interleukin-10 has been repetitively applied to modulate in vitro differentiation of monocyte-derived DCs with contradictive results (51-53). Allavena et al. (51) demonstrated that IL-10 
prevents DC differentiation by promoting a macrophage-like cell phenotype, whereas other studies reported that monocytes treated with IL-10 express markers associated with DCs $(52,53)$. Our group demonstrated that monocyte-derived DCs generated in the presence of IL-10 are a distinct subset of DCs with regulatory activities [(54), see next paragraph].

Interleukin-10 has been also applied to regulate already differentiated monocyte-derived immature $(55)$ or matured $(56,57)$ DCs. In both settings, DCs exposed to IL-10 treatment express reduced levels of MHC class II and costimulatory molecules, show decreased Ag-presenting capacity, and become regulatory cells with the ability to promote anergic T cells $(55,56)$ with suppressive activity in vitro (57). More recently, it has been demonstrated that DCs matured in the presence of IL-10, termed IL-10-induced DCs, consist of two phenotypically and functionally distinct populations: $\mathrm{CD} 83^{\text {high }} \mathrm{CCR} 7^{+}$and $\mathrm{CD} 83^{\text {low }} \mathrm{CCR} 7^{-}$ cells. The former cells display a strong migratory activity toward secondary lymphoid organs, have a stable phenotype, and induce in vitro T regulatory (Treg) cells with high suppressive activity. Based on these observations, the authors indicate that CD83 $3^{\text {high }}$ $\mathrm{CCR}^{+}$IL-10-induced DCs are promising candidates for cellbased approaches to induce/restore tolerance in vivo (58).

\section{DC-10 A DISTINCT POPULATION OF HUMAN TOLEROGENIC DENDRITIC CELLS (tolDCs)}

DC-10 are an inducible subset of human tolDCs characterized by the ability to secrete high levels of IL-10 in the absence of IL-12, and by the expression of a specific set of markers including CD14, CD16, CD11c, and CD11b, but not CD1a, M-DC8, or CD68 (54). Despite being generated from precursors in the presence of IL-10, DC-10 are mature cells expressing CD80, CD86, and HLA class II molecules. Importantly, DC-10 express a bunch of tolerogenic molecules such as ILT2, ILT3, ILT4, and HLA-G. Functional assays showed that, although DC-10 have a low stimulatory activity, they promote $\mathrm{T}$ cell anergy and induction of allo-specific T regulatory type $1(\operatorname{Tr} 1)$ cells $(50,54,59,60)$. Tr 1 cells are a subset of $\mathrm{CD}^{+} \mathrm{T}$ cells that co-express the integrin alpha2 subunit (CD49b) and the lymphocyte-activation gene 3 (LAG-3) (61), and secrete IL-10, TGF- $\beta$, variable amounts of IFN- $\gamma$ and low/no IL- 2 , IL- 4 , and IL-17. Tr1 cells suppress immune responses via the secretion of IL-10, TGF- $\beta$, and of granzyme B [as reviewed in Ref. $(13,62)$ ]. We demonstrated that DC-10 promote Tr1 cell differentiation via the IL-10-dependent ILT4/HLA-G pathway (54). Interestingly, DC-10-mediated induction of $\operatorname{Tr} 1$ cells is associated with high HLA-G expression (50).

DC-10 are present in peripheral blood and secondary lymphoid organs of healthy subjects and accumulate in human decidua in the first trimester of pregnancy (63). Interestingly, in peripheral blood of pregnant and non-pregnant women, the frequency of DC-10 is comparable, suggesting that either DC-10 migrate into decidua during pregnancy or are induced within the endometrium. Human decidua microenvironment is enriched in GM-CSF and IL-10 (64), both known to promote DC-10 differentiation, thereby decidual DC-10 can be either de novo induced from monocytes or derived from the conversion of resident decidual APCs. In the decidua of women with early miscarriage, DC-10 frequency is low (65), suggesting that in an inflammatory microenvironment differentiation of DC-10 is impaired. In line with this conclusion, in women with preeclampsia a subset of decidual CD $14^{+}$DC-SIGN ${ }^{+}$ APCs with reduced HLA-G and ILT4 expression and impaired ability to promote Tregs in vitro have been identified. The authors speculated that the reduced IL-10 levels observed in preeclampsia may lead to reduced HLA-G and ILT4 expression and impaired tolerogenic activity of these CD $14^{+}$DC-SIGN ${ }^{+}$APCs (66).

An altered frequency of DC-10 has been reported in peripheral blood of cancer patients. In patients affected by acute myeloid leukemia, a significantly higher frequency of DC-10 compared with that observed in healthy donors was described. Interestingly, the percentage of DC-10 is higher in patients with HLA-G-expressing blasts compared with patients with HLA-G negative blasts (67). Even though the primary source of HLA-G was unclear, it was postulated that the presence of HLA-G-expressing DC-10 is involved in sustaining the expression of HLA-G on blasts contributing to inhibition of the immune system promoting tumor immune-escape. According to this hypothesis, an increased frequency of DC-10 expressing high levels of HLA-G has been identified in peripheral blood of patients with gastric cancer. Interestingly, the percentage of HLA-G+DC-10 strongly associates with advanced disease stage (68).

Overall, these studies indicate that DC-10 represent a subset of regulatory DCs contributing to IL-10-mediating tolerance and immune-escape.

\section{DC-10 AS INDUCERS OF Ag-SPECIFIC Tr1 CELLS}

DC-10 have entered the clinical arena as inducers of Ag-specific $\operatorname{Tr} 1$ cells for tailoring Treg-based cell therapy. We established and validated in Good Manufacturing Practice (GMP) conditions an efficient and reproducible in vitro method to generate, with minimal cell manipulation, allo-specific $\operatorname{Tr} 1$ cells $(69,70)$. Indeed, stimulation of $\mathrm{T}$ cells with allo-DC-10 induces a population of allo-specific $\operatorname{Tr} 1$ cells actively suppressing allo-specific effector T cells $(50,54,59,60)$. Recently, two improved GMP-compatible protocols using DC-10 have been developed for generating $\operatorname{Tr} 1$ cells for cell-based therapy. The first method generates allospecific Tr1 cells (named T-allo10 cells, Bacchetta and Roncarolo, ClinicalTrials.gov identifier: NCT03198234) by culturing purified $\mathrm{CD}^{+} \mathrm{T}$ cells isolated from hematopoietic stem cell donor with patient-derived DC-10 in the presence of IL-10 (Figure 2). T-allo10 cells will be used as Tr1-based cell therapy in leukemia pediatric patients to prevent graft-versus-host disease (GvHD) (ClinicalTrials.gov identifier: NCT03198234). In the second protocol, $\mathrm{CD} 4^{+} \mathrm{T}$ cells isolated from patients on dialysis are cultured with donor-derived DC-10 in the presence of IL-10 to generate donor-specific Tr1-enriched cell medicinal product (named T10 cells) (Figure 2). T10 medicinal products will be injected in kidney transplant recipients to prevent graft rejection (60).

Stimulation of Th2 cells isolated from house dust mite allergic patients with autologous in vitro differentiated DC-10 pulsed with 


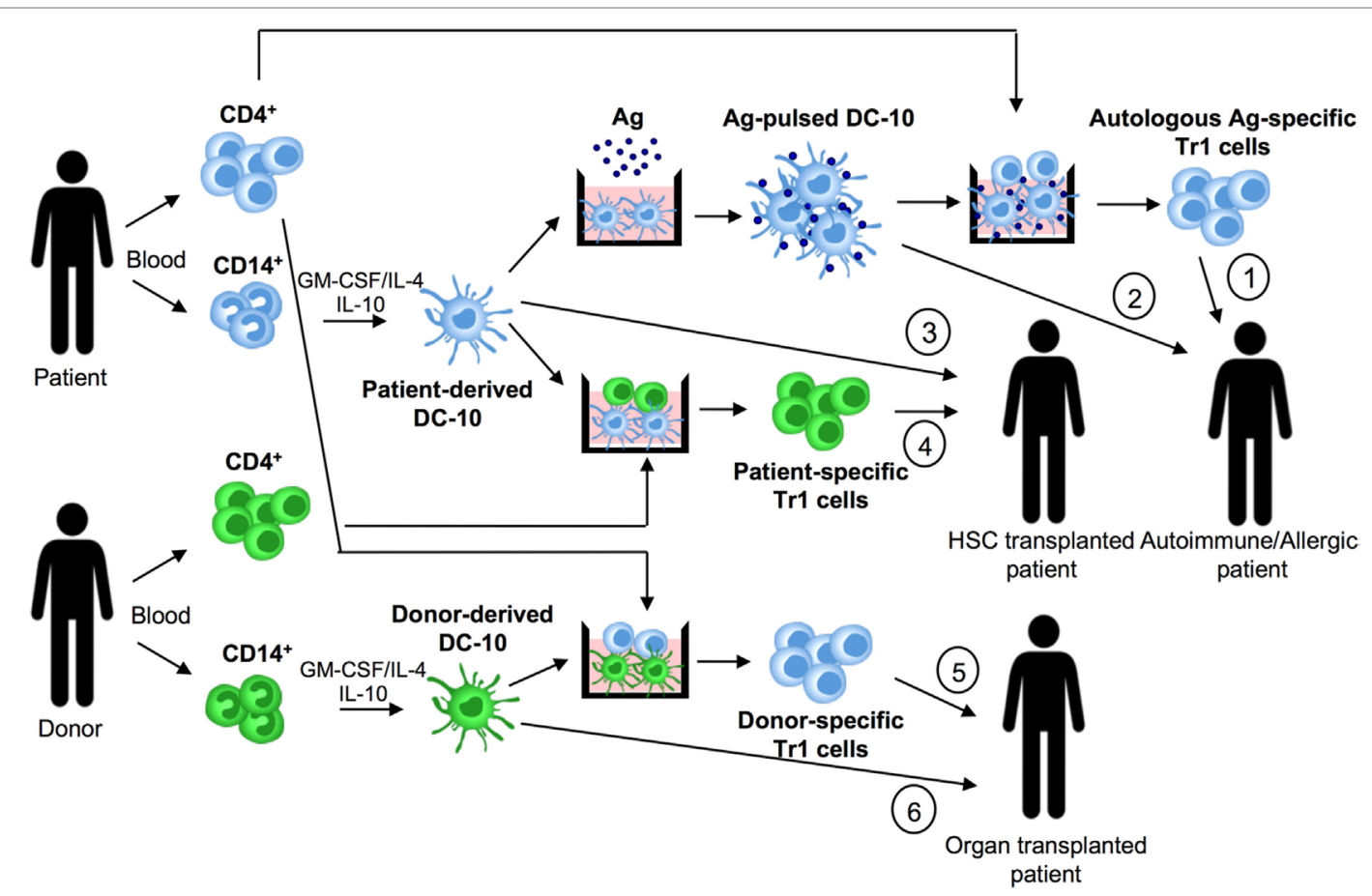

FIGURE 2 | DC-10 and cell therapy approaches. DC-10 are differentiated in vitro from CD14+ cells in the presence of GM-CSF/IL-4/IL-10. In allergy and autoimmunity, patient-derived DC-10 pulsed with the specific antigen (Ag) can be used to induce differentiation of autologous Ag-specific T regulatory type 1 (Tr1) cell products (1), or directly infused into patients (2). In hematopoietic stem cell (HSC) transplantation, patient-derived DC-10 can be used to differentiate patientspecific Tr1 cell products (3), or directly infused into transplanted patients (4). In solid organ transplantation, donor-derived DC-10 can be used to promote differentiation of donor-specific Tr1 cell products (5), or directly infused into transplanted patients (6).

the allergen promotes their conversion of into IL-10-producing $\mathrm{T}$ cells (59). Moreover, DC-10 differentiated from monocytes of healthy subjects and peanut allergic patients and pulsed with relevant allergen induced the differentiation of peanut-specific Tr1 cells (71).

These findings indicate that patient-derived DC-10 can be in vitro pulsed with a given $\mathrm{Ag}$ and used to generate Ag-specific $\operatorname{Tr} 1$ cells for Treg-based cell approaches aim at restoring tolerance in allergy and autoimmune diseases.

\section{DC-10-BASED CELL THERAPY}

The prominent role of DCs in promoting T-cell tolerance and the development of a GMP-compatible method to generate tolDC products allow their clinical application. Thus far, the few clinical trials performed demonstrated the safety and feasibility of tolDCbased cell therapies in the settings of autoimmunity and transplantation $(72,73)$. Nevertheless, the stability of the infused tolDC products and the maintenance of their tolerogenic properties in vivo remain open issues to be tackled for improving the safety and the efficacy of these therapies. Moreover, due to the increasing number of tolDCs that have been described, the optimal subset to be used as medicinal product is still to be defined. A comparative analysis of different populations of in vitro differentiated tolDCs examining their stability, cytokine production profile, and suppressive activity indicated that IL-10-modulated mature DCs are the best-suited cells for tolDC-based therapies $(74,75)$.
The observation that DC-10 are functionally more efficient than IL-10-modulated mature DCs in inducing hyporesponsiveness in allo-specific T cells (59) suggests that DC-10 represent a good alternative for cell-based approaches. Moreover, DC-10 are stable, since upon LPS stimulation, they maintain unaltered transcription profile and phenotype, and importantly the ability to induce Tr1 cells (76). DC-10 stability has been confirmed also in vivo, as their adoptive transfer modulates human $\mathrm{T}$ cell responses in a humanized mouse model. More recently, we demonstrated that DC-10 modulate allo iNKT cell induction and functions $(\mathrm{Wu}$, under revision), indicating a broaden immunoregulatory function of DC-10, not limited to the CD4 ${ }^{+} \mathrm{T}$ cell compartment. The potency, stability, and widespread immunoregulatory activity of DC-10 make feasible their application in clinical setting. Specifically, autologous DC-10 pulsed with a given Ag and allo-DC-10 can be infused in patients to restore tolerance in autoimmune diseases and allergy and to prevent allograft rejection and GvHD, respectively (Figure 2).

\section{CONCLUSION AND PERSPECTIVES}

The discovery that DC-10 can be generated in vitro and induce Ag-specific $\operatorname{Tr} 1$ cell differentiation prompt their development as a tool for clinical approaches aimed at promoting/restoring Ag-specific tolerance in immune-mediated diseases. Protocols to generate alloAg-specific $\operatorname{Tr} 1$ cells with DC-10 for adoptive $\operatorname{Tr} 1$ based cell therapy have been developed and validated in GMP and are currently using in clinical applications. We believe that 
DC-10 represent a good candidate for DC-based therapies as they modulate effector immune responses, including pathogenic $\mathrm{T}$ cells, while leading to long-term tolerance via the in vivo induction of Ag-specific $\operatorname{Tr} 1$ cells. Studies in humanized mouse models are ongoing to establish the best route and dose of administration, lifespan, and homing kinetic of DC-10 and will be instrumental to design clinical protocols to test the safety and efficacy of DC-10based cell therapy.

\section{AUTHOR CONTRIBUTIONS}

MC and GA wrote the manuscript. SG designed, supervised the drawing of the manuscript, and wrote the manuscript.

\section{REFERENCES}

1. Mosser DM, Zhang X. Interleukin-10: new perspectives on an old cytokine. Immunol Rev (2008) 226:205-18. doi:10.1111/j.1600-065X.2008.00706.x

2. Franke A, Balschun T, Karlsen TH, Sventoraityte J, Nikolaus S, Mayr G, et al. Sequence variants in IL10, ARPC2 and multiple other loci contribute to ulcerative colitis susceptibility. Nat Genet (2008) 40:1319-23. doi:10.1038/ ng.221

3. Glocker EO, Kotlarz D, Boztug K, Gertz EM, Schäffer AA, Noyan F, et al. Inflammatory bowel disease and mutations affecting the interleukin-10 receptor. N Engl J Med (2009) 361:2033-45. doi:10.1056/NEJMoa0907206

4. Engelhardt KR, Grimbacher B. IL-10 in humans: lessons from the gut, IL-10/ IL-10 receptor deficiencies, and IL-10 polymorphisms. Curr Top Microbiol Immunol (2014) 380:1-18. doi:10.1007/978-3-662-43492-5_1

5. Moore KW, de Waal Malefyt R, Coffman RL, O'Garra A. Interleukine-10 and the interleukine-10 receptor. Annu Rev Immunol (2001) 19:683-765. doi:10.1146/annurev.immunol.19.1.683

6. Groux H, Cottrez F. The complex role of interleukin-10 in autoimmunity. J Autoimmun (2003) 20:281-5. doi:10.1016/S0896-8411(03)00044-1

7. Roncarolo MG, Gregori S, Battaglia M, Bacchetta R, Fleischhauer K, Levings MK. Interleukin-10-secreting type 1 regulatory $\mathrm{T}$ cells in rodents and humans. Immunol Rev (2006) 212:28-50. doi:10.1111/j.0105-2896. 2006.00420.x

8. Vieira P, de Waal-Malefyt R, Dang MN, Johnson KE, Kastelein R, Fiorentino DF, et al. Isolation and expression of human cytokine synthesis inhibitory factor cDNA clones: homology to Epstein-Barr virus open reading frame BCRFI. Proc Natl Acad Sci U S A (1991) 88:1172-6. doi:10.1073/pnas.88.4.1172

9. Roncarolo MG, Yssel H, Touraine JL, Betuel H, De Vries JE, Spits H. Autoreactive $T$ cell clones specific for class I and class II HLA antigens isolated from a human chimera. J Exp Med (1988) 167:1523-34. doi:10.1084/jem.167.5.1523

10. Saraiva M, Christensen JR, Veldhoen M, Murphy TL, Murphy KM, O'Garra A. Interleukin-10 production by Th1 cells requires interleukin-12-induced STAT4 transcription factor and ERK MAP kinase activation by high antigen dose. Immunity (2009) 31:209-19. doi:10.1016/j.immuni.2009.05.012

11. Chen Q, Daniel V, Maher DW, Hersey P. Production of IL-10 by melanoma cells: examination of its role in immunosuppression mediated by melanoma. Int J Cancer (1994) 56:755-60. doi:10.1002/ijc.2910560524

12. Itakura E, Huang RR, Wen DR, Paul E, Wünsch PH, Cochran AJ. IL-10 expression by primary tumor cells correlates with melanoma progression from radial to vertical growth phase and development of metastatic competence. Mod Pathol (2011) 24:801-9. doi:10.1038/modpathol.2011.5

13. Gregori S, Goudy KS, Roncarolo MG. The cellular and molecular mechanisms of immuno-suppression by human type 1 regulatory T cells. Front Immunol (2012) 3:30. doi:10.3389/fimmu.2012.00030

14. Verma R, Balakrishnan L, Sharma K, Khan AA, Advani J, Gowda H, et al. A network map of Interleukin-10 signaling pathway. J Cell Commun Signal (2016) 10:61-7. doi:10.1007/s12079-015-0302-x

15. Donnelly RP, Dickensheets H, Finbloom DS. The interleukin-10 signal transduction pathway and regulation of gene expression in mononuclear phagocytes. JInterferon Cytokine Res (1999) 19:563-73. doi:10.1089/ 107999099313695

\section{ACKNOWLEDGMENTS}

The authors thank Dr. Daniele Avancini (Mechanisms of Peripheral Tolerance Unit, SR-TIGET, San Raffaele Scientific Institute, Milan, Italy) for critical reading of the manuscript. This work was supported by grant to SG from the Italian Telethon Foundation (TGT17G01) Associazione Italiana per la Lotta contro il Cancro (AIRC) project AIRC IG 18540, and from COST (European Cooperation in Science and Technology) and the Action BM1305 A-FAACT (http://www.afactt.eu) and the COST Action BM1404 Mye-EUNITER (http://www.myeeuniter.eu). COST is part of the EU Framework Programme Horizon 2020.

16. Murray PJ. Understanding and exploiting the endogenous interleukin-10/ STAT3-mediated anti-inflammatory response. Curr Opin Pharmacol (2006) 6:379-86. doi:10.1016/j.coph.2006.01.010

17. Lang R, Patel D, Morris JJ, Rutschman RL, Murray PJ. Shaping gene expression in activated and resting primary macrophages by IL-10. J Immunol (2002) 169:2253-63. doi:10.4049/jimmunol.169.5.2253

18. Hutchins AP, Diez D, Miranda-Saavedra D. The IL-10/STAT3-mediated anti-inflammatory response: recent developments and future challenges. Brief Funct Genomics (2013) 12:489-98. doi:10.1093/bfgp/elt028

19. Kuwata H, Watanabe Y, Miyoshi H, Yamamoto M, Kaisho T, Takeda K, et al. IL-10-inducible Bcl-3 negatively regulates LPS-induced TNF-alpha production in macrophages. Blood (2003) 102:4123-9. doi:10.1182/blood-200304-1228

20. Smith AM, Qualls JE, O'Brien K, Balouzian L, Johnson PF, Schultz-Cherry S, et al. A distal enhancer in Il12b is the target of transcriptional repression by the STAT3 pathway and requires the basic leucine zipper (B-ZIP) protein NFIL3. J Biol Chem (2011) 286:23582-90. doi:10.1074/jbc.M111.249235

21. Kobayashi T, Matsuoka K, Sheikh SZ, Elloumi HZ, Kamada N, Hisamatsu T, et al. NFIL3 is a regulator of IL-12 p40 in macrophages and mucosal immunity. J Immunol (2011) 186:4649-55. doi:10.4049/jimmunol.1003888

22. Berlato C, Cassatella MA, Kinjyo I, Gatto L, Yoshimura A, Bazzoni F. Involvement of suppressor of cytokine signaling-3 as a mediator of the inhibitory effects of IL-10 on lipopolysaccharide-induced macrophage activation. J Immunol (2002) 168:6404-11. doi:10.4049/jimmunol.168.12.6404

23. Yasukawa H, Sasaki A, Yoshimura A. Negative regulation of cytokine signaling pathways. Annu Rev Immunol (2000) 18:143-64. doi:10.1146/annurev. immunol.18.1.143

24. Yasukawa H, Ohishi M, Mori H, Murakami M, Chinen T, Aki D, et al. IL-6 induces an anti-inflammatory response in the absence of SOCS 3 in macrophages. Nat Immunol (2003) 4:551-6. doi:10.1038/ni938

25. Wang P, Wu P, Siegel MI, Egan RW, Billah MM. Interleukin (IL)-10 inhibits nuclear factor $\mathrm{\kappa B}(\mathrm{NF \kappa B})$ activation in human monocytes. IL-10 and IL-4 suppress cytokine synthesis by different mechanisms. J Biol Chem (1995) 270:9558-63. doi:10.1074/jbc.270.16.9558

26. Clarke CJ, Hales A, Hunt A, Foxwell BM. IL-10-mediated suppression of TNF-alpha production is independent of its ability to inhibit NF kappa B activity. Eur J Immunol (1998) 28:1719-26. doi:10.1002/(SICI)1521-4141 (199805)28:05<1719::AID-IMMU1719>3.0.CO;2-Q

27. Driessler F, Venstrom K, Sabat R, Asadullah K, Schottelius AJ. Molecular mechanisms of interleukin-10-mediated inhibition of NF-kappaB activity: a role for p50. Clin Exp Immunol (2004) 135:64-73. doi:10.1111/j.13652249.2004.02342.x

28. Schottelius AJ, Mayo MW, Sartor RB, Baldwin AS Jr. Interleukin-10 signaling blocks inhibitor of kappab kinase activity and nuclear factor kappaB DNA binding. J Biol Chem (1999) 274:31868-74. doi:10.1074/jbc.274.45.31868

29. Bhattacharyya S, Sen P, Wallet M, Long B, Baldwin AS Jr, Tisch R. Immunoregulation of dendritic cells by IL-10 is mediated through suppression of the PI3K/Akt pathway and of IkappaB kinase activity. Blood (2004) 104:1100-9. doi:10.1182/blood-2003-12-4302

30. Knödler A, Schmidt SM, Bringmann A, Weck MM, Brauer KM, Holderried TA, et al. Post-transcriptional regulation of adapter molecules by IL-10 
inhibits TLR-mediated activation of antigen-presenting cells. Leukemia (2009) 23:535-44. doi:10.1038/leu.2008.301

31. Bours V, Franzoso G, Azarenko V, Park S, Kanno T, Brown K, et al. The oncoprotein Bcl-3 directly transactivates through kappa B motifs via association with DNA-binding p50B homodimers. Cell (1993) 72:729-39. doi:10.1016/0092-8674(93)90401-B

32. Wessells J, Baer M, Young HA, Claudio E, Brown K, Siebenlist U, et al. BCL-3 and NF-kappaB p50 attenuate lipopolysaccharide-induced inflammatory responses in macrophages. J Biol Chem (2004) 279:49995-50003. doi:10.1074/ jbc.M404246200

33. de Waal Malefyt R, Haanen J, Spits H, Roncarolo MG, te Velde A, Figdor C, et al. Interleukin 10 (IL-10) and viral IL-10 strongly reduce antigen-specific human $\mathrm{T}$ cell proliferation by diminishing the antigen-presenting capacity of monocytes via downregulation of class II major histocompatibility complex expression. J Exp Med (1991) 174:915-24. doi:10.1084/jem.174.4.915

34. Ding L, Linsley PS, Huang LY, Germain RN, Shevach EM. IL-10 inhibits macrophage costimulatory activity by selectively inhibiting the up-regulation of B7 expression. J Immunol (1993) 151:1224-34.

35. Willems F, Marchant A, Delville JP, Gérard C, Delvaux A, Velu T, et al. Interleukin-10 inhibits B7 and intercellular adhesion molecule-1 expression on human monocytes. Eur J Immunol (1994) 24:1007-9. doi:10.1002/ eji. 1830240435

36. Koppelman B, Neefjes JJ, de Vries JE, de Waal Malefyt R. Interleukin-10 down-regulates MHC class II $\alpha \beta$ peptide complexes at the plasma membrane of monocytes by affecting arrival and recycling. Immunity (1997) 7:861-71. doi:10.1016/S1074-7613(00)80404-5

37. Williams L, Bradley L, Smith A, Foxwell B. Signal transducer and activator of transcription 3 is the dominant mediator of the anti-inflammatory effects of IL-10 in human macrophages. J Immunol (2004) 172:567-76. doi:10.4049/ jimmunol.172.1.567

38. Quinn SR, O'Neill LA. The role of microRNAs in the control and mechanism of action of IL-10. Curr Top Microbiol Immunol (2014) 380:145-55. doi:10.1007/978-3-662-43492-5_7

39. McCoy CE, Sheedy FJ, Qualls JE, Doyle SL, Quinn SR, Murray PJ, et al. IL-10 inhibits miR-155 induction by toll-like receptors. J Biol Chem (2010) 285:20492-8. doi:10.1074/jbc.M110.102111

40. Rossato M, Curtale G, Tamassia N, Castellucci M, Mori L, Gasperini S, et al. IL-10-induced microRNA-187 negatively regulates TNF-, IL-6, and IL-12p40 production in TLR4-stimulated monocytes. Proc Natl Acad Sci U S A (2012) 109:E3101-10. doi:10.1073/pnas.1209100109

41. Sheedy FJ, Palsson-McDermott E, Hennessy EJ, Martin C, O’Leary JJ, Ruan Q, et al. Negative regulation of TLR4 via targeting of the proinflammatory tumor suppressor PDCD4 by the microRNA miR-21. Nat Immunol (2010) 11:141-7. doi:10.1038/ni.1828

42. Ricchetti GA, Williams LM, Foxwell BM. Heme oxygenase 1 expression induced by IL-10 requires STAT- 3 and phosphoinositol- 3 kinase and is inhibited by lipopolysaccharide. J Leukoc Biol (2004) 76:719-26. doi:10.1189/ jlb.0104046

43. Chauveau C, Rémy S, Royer PJ, Hill M, Tanguy-Royer S, Hubert FX, et al. Heme oxygenase- 1 expression inhibits dendritic cell maturation and proinflammatory function but conserves IL-10 expression. Blood (2005) 106:1694-702. doi:10.1182/blood-2005-02-0494

44. Chang CC, Ciubotariu R, Manavalan JS, Yuan J, Colovai AI, Piazza F, et al. Tolerization of dendritic cells by $\mathrm{T}(\mathrm{S})$ cells: the crucial role of inhibitory receptors ILT3 and ILT4. Nat Immunol (2002) 3:237-43. doi:10.1038/ ni760

45. Weis $\mathrm{N}$, Weigert A, von Knethen A, Brüne B. Heme oxygenase-1 contributes to an alternative macrophage activation profile induced by apoptotic cell supernatants. Mol Biol Cell (2009) 20:1280-8. doi:10.1091/mbc.E0810-1005

46. Naito Y, Takagi T, Higashimura Y. Heme oxygenase-1 and anti-inflammatory M2 macrophages. Arch Biochem Biophys (2014) 564:83-8. doi:10.1016/j. abb.2014.09.005

47. Colonna M, Navarro F, Bellón T, Llano M, García P, Samaridis J, et al. A common inhibitory receptor for major histocompatibility complex class I molecules on human lymphoid and myelomonocytic cells. J Exp Med (1997) 186:1809-18. doi:10.1084/jem.186.11.1809

48. Cella M, Döhring C, Samaridis J, Dessing M, Brockhaus M, Lanzavecchia A, et al. A novel inhibitory receptor (ILT3) expressed on monocytes, macrophages, and dendritic cells involved in antigen processing. J Exp Med (1997) 185:1743-51. doi:10.1084/jem.185.10.1743

49. Moreau P, Adrian-Cabestre F, Menier C, Guiard V, Gourand L, Dausset $\mathrm{J}$, et al. IL-10 selectively induces HLA-G expression in human trophoblasts and monocytes. Int Immunol (1999) 11:803-11. doi:10.1093/ intimm/11.5.803

50. Amodio G, Comi M, Tomasoni D, Gianolini ME, Rizzo R, LeMaoult J, et al. HLA-G expression levels influence the tolerogenic activity of human DC-10. Haematologica (2015) 100:548-57. doi:10.3324/haematol.2014.113803

51. Allavena P, Piemonti L, Longoni D, Bernasconi S, Stoppacciaro A, Ruco L, et al. IL-10 prevents the differentiation of monocytes to dendritic cells but promotes their maturation to macrophages. Eur J Immunol (1998) 28:359-69. doi:10.1002/(SICI) 1521-4141(199801)28:01<359::AID-IMMU359> 3.0.CO;2-4

52. Ancuta P, Weiss L, Haeffner-Cavaillon N. CD14+CD16++ cells derived in vitro from peripheral blood monocytes exhibit phenotypic and functional dendritic cell-like characteristics. Eur J Immunol (2000) 30:1872-83. doi:10.1002/1521-4141(200007)30:7<1872::AID-IMMU1872>3.0.CO;2-2

53. Velten FW, Duperrier K, Bohlender J, Metharom P, Goerdt S. A gene signature of inhibitory MHC receptors identifies a BDCA3(+) subset of IL-10-induced dendritic cells with reduced allostimulatory capacity in vitro. Eur J Immunol (2004) 34:2800-11. doi:10.1002/eji.200324732

54. Gregori S, Tomasoni D, Pacciani V, Scirpoli M, Battaglia M, Magnani CF, et al. Differentiation of type $1 \mathrm{~T}$ regulatory cells (Tr1) by tolerogenic DC-10 requires the IL-10-dependent ILT4/HLA-G pathway. Blood (2010) 116:935-44. doi:10.1182/blood-2009-07-234872

55. Zheng Z, Narita M, Takahashi M, Liu A, Furukawa T, Toba K, et al. Induction of $\mathrm{T}$ cell anergy by the treatment with IL-10-treated dendritic cells. Comp Immunol Microbiol Infect Dis (2004) 27:93-103. doi:10.1016/S01479571(03)00054-7

56. Steinbrink K, Wölfl M, Jonuleit H, Knop J, Enk AH. Induction of tolerance by IL-10-treated dendritic cells. J Immunol (1997) 159:4772-80.

57. Steinbrink K, Graulich E, Kubsch S, Knop J, Enk AH. CD4(+) and CD8(+) anergic $\mathrm{T}$ cells induced by interleukin-10-treated human dendritic cells display antigen-specific suppressor activity. Blood (2002) 99:2468-76. doi:10.1182/ blood.V99.7.2468

58. Kryczanowsky F, Raker V, Graulich E, Domogalla MP, Steinbrink K. IL-10modulated human dendritic cells for clinical use: identification of a stable and migratory subset with improved tolerogenic activity. J Immunol (2016) 197:3607-17. doi:10.4049/jimmunol.1501769

59. Pacciani V, Gregori S, Chini L, Corrente S, Chianca M, Moschese V, et al. Induction of anergic allergen-specific suppressor $\mathrm{T}$ cells using tolerogenic dendritic cells derived from children with allergies to house dust mites. J Allergy Clin Immunol (2010) 125:727-36. doi:10.1016/j.jaci.2009.12.004

60. Mfarrej B, Tresoldi E, Stabilini A, Paganelli A, Caldara R, Secchi A, et al. Generation of donor-specific Trl cells to be used after kidney transplantation and definition of the timing of their in vivo infusion in the presence of immunosuppression. J Transl Med (2017) 15:40. doi:10.1186/ s12967-017-1133-8

61. Gagliani N, Magnani CF, Huber S, Gianolini ME, Pala M, Licona-Limon P, et al. Coexpression of CD49b and LAG-3 identifies human and mouse T regulatory type 1 cells. Nat Med (2013) 19:739-46. doi:10.1038/nm.3179

62. Roncarolo MG, Gregori S, Bacchetta R, Battaglia M. Tr1 cells and the counter-regulation of immunity: natural mechanisms and therapeutic applications. Curr Top Microbiol Immunol (2014) 380:39-68. doi:10.1007/978-3662-43492-5_3

63. Amodio G, Mugione A, Sanchez AM, Viganò P, Candiani M, Somigliana E, et al. HLA-G expressing DC-10 and CD4(+) T cells accumulate in human decidua during pregnancy. Hum Immunol (2013) 74:406-11. doi:10.1016/j. humimm.2012.11.031

64. Shakhawat A, Shaikly V, Elzatma E, Mavrakos E, Jabeen A, Fernández N. Interaction between HLA-G and monocyte/macrophages in human pregnancy. J Reprod Immunol (2010) 85:40-6. doi:10.1016/j.jri.2010. 02.004

65. Gregori S, Amodio G, Comi M, Roncarolo MG, Panina-Bordignon P. Regulatory IL-10-producing DC (DC-10) are central determinants in HLAG-mediated tolerance. Tissue Antigens (2015) 85:310-310.

66. Hsu P, Santner-Nanan B, Dahlstrom JE, Fadia M, Chandra A, Peek M, et al. Altered decidual DC-SIGN+antigen-presenting cells and impaired 
regulatory T-cell induction in preeclampsia. Am J Pathol (2012) 181:2149-60. doi:10.1016/j.ajpath.2012.08.032

67. Locafaro G, Amodio G, Tomasoni D, Tresoldi C, Ciceri F, Gregori S. HLA-G expression on blasts and tolerogenic cells in patients affected by acute myeloid leukemia. J Immunol Res (2014) 2014:636292. doi: $10.1155 / 2014 / 636292$

68. Xu DP, Shi WW, Zhang TT, Lv HY, Li JB, Lin A, et al. Elevation of HLA-Gexpressing DC-10 cells in patients with gastric cancer. Hum Immunol (2016) 77:800-4. doi:10.1016/j.humimm.2016.01.003

69. Bacchetta R, Gregori S, Serafini G, Sartirana C, Schulz U, Zino E, et al. Molecular and functional characterization of allogantigen-specific anergic T cells suitable for cell therapy. Haematologica (2010) 95:2134-43.doi:10.3324/ haematol.2010.025825

70. GregoriS, RoncaroloMG,BacchettaR. Methodsforin vitrogeneration ofhuman type 1 regulatory T cells. Methods Mol Biol (2011) 677:31-46. doi:10.1007/ 978-1-60761-869-0_3

71. Pellerin L, Jenks JA, Chinthrajah S, Dominguez T, Block W, Zhou X. Peanutspecific type 1 regulatory $\mathrm{T}$ cells induced in vitro from allergic subjects are functionally impaired. JAllergy Clin Immunol (2018) 141:202-13.e8. doi:10.1016/j.jaci.2017.05.045

72. Moreau A, Varey E, Bériou G, Hill M, Bouchet-Delbos L, Segovia M, et al. Tolerogenic dendritic cells and negative vaccination in transplantation: from rodents to clinical trials. Front Immunol (2012) 3:218. doi:10.3389/ fimmu.2012.00218
73. Phillips BE, Garciafigueroa Y, Trucco M, Giannoukakis N. Clinical tolerogenic dendritic cells: exploring therapeutic impact on human autoimmune disease. Front Immunol (2017) 8:1279. doi:10.3389/fimmu.2017.01279

74. Naranjo-Gómez M, Raïch-Regué D, Oñate C, Grau-López L, Ramo-Tello C, Pujol-Borrell R, et al. Comparative study of clinical grade human tolerogenic dendritic cells. J Transl Med (2011) 9:89. doi:10.1186/1479-5876-9-89

75. Boks MA, Kager-Groenland JR, Haasjes MS, Zwaginga JJ, van Ham SM, ten Brinke A. IL-10-generated tolerogenic dendritic cells are optimal for functional regulatory $\mathrm{T}$ cell induction - a comparative study of human clinical-applicable DC. Clin Immunol (2012) 142:332-42. doi:10.1016/ j.clim.2011.11.011

76. Amodio G, Gregori S. Human tolerogenic DC-10: perspectives for clinical applications. Transplant Res (2012) 1:14. doi:10.1186/2047-1440-1-14

Conflict of Interest Statement: The authors declare that the research was conducted in the absence of any commercial or financial relationships that could be construed as a potential conflict of interest.

Copyright (c) 2018 Comi, Amodio and Gregori. This is an open-access article distributed under the terms of the Creative Commons Attribution License (CC $B Y)$. The use, distribution or reproduction in other forums is permitted, provided the original author(s) and the copyright owner are credited and that the original publication in this journal is cited, in accordance with accepted academic practice. No use, distribution or reproduction is permitted which does not comply with these terms. 